\title{
Effect of Immersion in Warm Water on Bonding Strength between Autopolymerizing Resin and Denture Base Resin
}

\author{
Takayuki Ueda, DDS, PhD, Miki Ryuzaki, DDS, Harunaka Ishii, DDS, PhD, \\ Tetsuya Sugiyama DDS, PhD, and Kaoru Sakurai, DDS, PhD \\ Department of Removable Prosthodontics \& Gerodontology, Tokyo Dental College, Chiba, Japan
}

\section{Clinical Significance}

This study evaluated a method for enhancing the bonding strength between denture base resins and self-curing resins. It was demonstrated that for selfcuring resins to which barbituric acid derivatives had been added to aid as polymerization initiators, greater bonding strength was obtained with immersion in warm water at the time of initiation of the polymerization.

\begin{abstract}
Purpose: The purpose of this study was to investigate the influence of immersion in warm water and the timing of the immersion on bonding strength between a built-up self-curing resin and a heat-cured denture base resin.

Methods: In this study, self-curing resins (Unifast II or Unifast Trad) were built up on denture base resins after surface treatment of the latter with or without primer. The specimens were cured under three conditions (immersion in warm water for $10 \mathrm{~s}$ after build-up (E), immersion in warm water for $210 \mathrm{~s}$ after build-up (L), and without immersion in warm water $(\mathrm{N})$ ), and shear bond strength and failure patterns were measured.

Results: For Unifast II without primer, there were significant differences in shear bonding strength between conditions $\mathrm{E}$ and $\mathrm{L}$, or conditions $\mathrm{E}$ and N. A cohesion failure rate of $70 \%$ was noted under condition E. Bonding strength of Unifast II with primer also differed significantly between conditions $\mathrm{E}$ and L. There were no correlations between the failure patterns and the curing conditions. For the case of Unifast Trad without primer, no significant difference was in the bonding strength were observed under the different conditions, whereas for that with primer, significant differences in bonding strength were observed
\end{abstract}

Corresponding to: Dr Takayuki Ueda

Department of Removable Prosthodontics \& Gerodontology,

Tokyo Dental College,

1-2-2 Masago, Mihama-ku, Chiba city, Chiba 261-8502, Japan

Tel +81-43-270-3933, Fax +81-43-270-3935

E-mail: uedat@tdc.ac.jp

Received on February 9, 2006 / Accepted on June 2, 2006 between conditions L and N. Since the failure pattern in all cases was represented by cohesion failure, there was no statistically significant relationship between the curing conditions and the failure pattern.

Conclusion: Immersion in warm water at the beginning of the polymerization response enhances the bonding strength of Unifast II to denture base resin without primer. On the other hand, for the cases of both Unifast II with primer and that of Unifast Trad with and without primer, there was no correlation between immersion in warm water during polymerization of the resin and bonding strength.

Key words: self-curing resin, denture base resin, repair of denture, bonding strength

\section{Introduction}

Second-interface failures between heat-cured denture base acrylic resins and methyl-methacrylate self-curing resins after denture repair are sometimes observed in clinical practice, which have been attributed to defects in the bonding between these resins. Previous reports ${ }^{1-5}$ have demonstrated that physical and chemical surface treatments of the denture base increase the bonding strength between the self-curing resin and the denture base resin. Ogawa et $\mathrm{al}^{6}$ reported that polymerization of the self-curing resin at high temperatures increased the bending strength, although this also increased polymerization shrinkage. Hoshiai et $\mathrm{al}^{7}$ assessed the effects of the interval from build-up of a resin to its immersion in warm water, the water temperature, and the duration of immersion on the bonding strength of a self-curing resin to another cured self-curing resin. They reported that an immersion time of $60 \mathrm{~s}$ in water at $50^{\circ} \mathrm{C}$ or above was an appropriate condition.

These reports suggest that the surface treatment method and temperature during polymerization influence the bonding strength; however 
a procedure for obtaining optimum bonding between a self-curing resin and a denture base resin in denture repair has yet to be established. Therefore, this study was conducted to investigate the relationship between the bonding strength of a heat-cured denture base acrylic resin and a methyl-methacrylate self-curing resin and the type of surface treatment, immersion in warm water, and the time until immersion.

\section{Materials and methods}

An adherent resin plate was prepared with a heat-cured denture base resin (Quick Acron, GC Corporation, Tokyo, Japan); the Quick Acron resin plates were prepared by the wet heat polymerization method and polished with emery paper up to \#600. They were then immersed in water at $37^{\circ} \mathrm{C}$ for $48 \mathrm{~h}$ or more, to achieve a state of saturated water absorption.

Prior to the build-up of the self-curing resin, the denture base resin was subjected to two types of surface treatments, one involving a $10^{-\mathrm{s}}$ airblow, and the other involving a 5-s application of a dichloromethane-based primer (Resin Primer, GC Corporation).

After surface treatment of the adherent face of the denture base resin, the same operator carried out the build-up of the self-curing resin on the denture base resin using the brush-on technique to achieve a uniform performance. An acrylic tube $5 \mathrm{~mm}$ in diameter and $5 \mathrm{~mm}$ in height was used to define the adherent area on the adherent face. Two types of self-curing resins consisting of the same main component but different polymerization initiators were used for the build-up. Resins with barbituric acid derivatives (Unifast II, GC Corporation) or an aromatic tertiary amine (N, N-dimethyl-p-toluidine) (Unifast Trad, GC Corporation) were used as the polymerization initiator.

During the polymerization after build-up, the specimens were maintained under the following three curing conditions: condition $\mathrm{N}$, in which the specimens were maintained in air at room temperature $\left(20^{\circ} \mathrm{C}\right)$ for $30 \mathrm{~min}$ after build-up; condition E, 10 s after build-up, the specimens were immersed in water at $50^{\circ} \mathrm{C}$ for $5 \mathrm{~min}$, and then exposed to air; condition $\mathrm{L}$, in which $3 \mathrm{~min}$ and 30s (manufacturer's recommended termination time of initial curing) after the build-up, the specimens were immersed in water at $50^{\circ} \mathrm{C}$ for 5
Table 1 Conditions of each group and results for shear bonding strength and the failure patterns.

\begin{tabular}{|c|c|c|c|c|c|}
\hline $\begin{array}{l}\text { self-curing } \\
\text { resin }\end{array}$ & $\begin{array}{l}\text { surface } \\
\text { treatment }\end{array}$ & $\begin{array}{l}\text { curing } \\
\text { condition }\end{array}$ & $\begin{array}{l}\text { mean value of } \\
\text { shear bonding } \\
\text { strength (MPa) }\end{array}$ & $\begin{array}{l}\text { standard deviation } \\
\text { of shear bonding } \\
\text { strength (MPa) }\end{array}$ & $\begin{array}{l}\text { cohesion } \\
\text { failure } \\
(\%)\end{array}$ \\
\hline Unifast II & Airblow & $\mathrm{E}$ & 11.0 & 1.7 & 70 \\
\hline Unifast II & Airblow & $\mathrm{L}$ & 8.3 & 0.8 & 0 \\
\hline Unifast II & Airblow & $\mathrm{N}$ & 8.9 & 0.5 & 0 \\
\hline Unifast II & $\begin{array}{c}\text { Airblow } \\
+ \\
\text { Primer }\end{array}$ & $\mathrm{E}$ & 12.6 & 2.2 & 100 \\
\hline Unifast II & $\begin{array}{c}\text { Airblow } \\
+ \\
\text { Primer }\end{array}$ & $\mathrm{L}$ & 16.1 & 3.5 & 90 \\
\hline Unifast II & $\begin{array}{c}\text { Airblow } \\
+ \\
\text { Primer }\end{array}$ & $\mathrm{N}$ & 15.7 & 3.9 & 90 \\
\hline Unifast Trad & Airblow & $\mathrm{E}$ & 15.4 & 3.9 & 10 \\
\hline Unifast Trad & Airblow & $\mathrm{L}$ & 14.1 & 3.5 & 20 \\
\hline Unifast Trad & Airblow & $\mathrm{N}$ & 14.6 & 5.1 & 30 \\
\hline Unifast Trad & $\begin{array}{c}\text { Airblow } \\
\quad+ \\
\text { Primer }\end{array}$ & $\mathrm{E}$ & 16.7 & 3.8 & 100 \\
\hline Unifast Trad & $\begin{array}{c}\text { Airblow } \\
+ \\
\text { Primer }\end{array}$ & $\mathrm{L}$ & 16.1 & 3.9 & 100 \\
\hline Unifast Trad & $\begin{array}{c}\text { Airblow } \\
+ \\
\text { Primer }\end{array}$ & $\mathrm{N}$ & 20.6 & 3.7 & 100 \\
\hline
\end{tabular}

min, and then exposed to air.

Consequently, 12 types of specimens were generated through a combination of the three polymerization conditions and the two surface treatment methods and two self-curing resins (Table 1). Ten specimens were prepared for each condition.

After polymerization under each condition, all the specimens were immersed in water at $37^{\circ} \mathrm{C}$ for $24 \mathrm{~h}$. The shear bonding strength was then measured by the shear bonding test (at the crosshead speed of $1 \mathrm{~mm} / \mathrm{min}$ ) according to the method of Shimizu et $\mathrm{al}^{8}$ using a precision universal tester, the AUTOGRAPH AG-A (Shimadzu Corporation, Kyoto, Japan). After the test, the fractured surfaces of the specimens were evaluated using an optical microscope (x50) and classified into interface or cohesion failures. If any part of the specimen surface exhibited cohesion failure, it was classified as a case of cohesion failure. Three skilled operators conducted the evaluations independently. The final evaluation was made by the majority.

For the analysis of the bonding strength, the Student's t-test was used to compare the two conditions, and one-way analysis of variance and Scheffé's test were used for multiple comparisons. The chi-square and exact tests were used to evaluate the failure patterns. Significance 

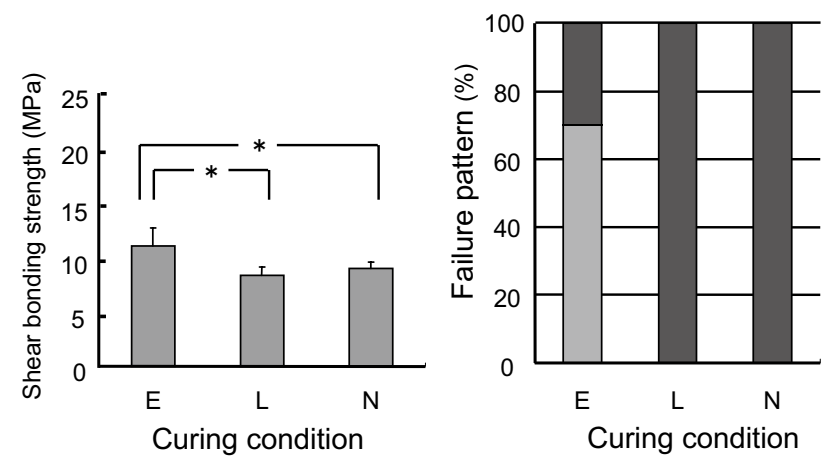

Interface failure cohesion failure

Fig. 1 Results for shear bonding strength and failure pattern for Unifast II to denture base resin surface-treated without primer $(\mathrm{N}=10) .(*: P<.05$, T-bar: S.D. $)$

level was set at 0.05 for all the analyses. The SPSS11.0J (SPSS Inc., Illinois, U.S.A.) was used for statistical analyses.

\section{Results}

The results of the shear bonding test and the failure patterns are shown in Table 1. There was a significant difference in the shear bonding strength under all curing conditions for Unifast II and Unifast Trad and the denture base resins subjected to surface treatment without primer. There was also a significant correlation between the type of self-curing resin and the failure pattern under curing condition $\mathrm{E}$, where the specimens were immersed in warm water at the beginning of polymerization. However, no significant correlation was observed between the type of self-curing resin and the failure pattern under curing conditions L and N. Furthermore, no significant difference was found in the shear bonding strength under any curing condition, and no significant correlation was observed between the type of self-curing resin and the failure pattern for Unifast II and Unifast Trad and denture base resin subjected to surface treatment with primer.

A significant difference in bonding strength was found under curing conditions $\mathrm{L}$ and $\mathrm{N}$ for Unifast II and denture base resin after surface treatment with and without primer. No significant difference was observed, however, under any of the other curing condition. No significant correlation was found for Unifast II and denture
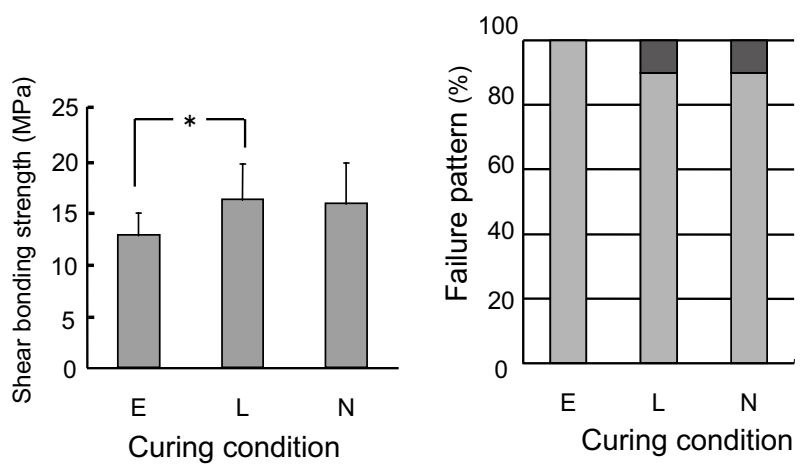

Interface failure cohesion failure

Fig. 2 Results for shear bonding strength and failure pattern for Unifast II to denture base resin surface-treated with primer $(\mathrm{N}=10) .(*: P<.05$, T-bar: S.D. $)$

base resin subjected to surface treatment with or without primer and the failure pattern under condition E, however significant correlations between the above parameters were observed under all the other curing conditions.

A comparison among curing conditions showed significant differences in the bonding strength of Unifast II to denture base resin surface-treated without primer between conditions $\mathrm{E}$ and $\mathrm{L}$, and conditions E and N (Fig. 1 Left). For the case of bonding of Unifast II to denture base resin surface-treated without primer, $7(70 \%)$ of the specimens exhibited surface cohesion failure under condition $\mathrm{E}$, and the correlation between the curing condition and the failure pattern was significant (Fig. 1 Right). Significant differences in the bonding strength of Unifast II to denture base resin surface-treated with primer were also observed between curing conditions $\mathrm{E}$ and L (Fig. 2 Left). Most resins exhibited cohesion failure; therefore, there was no significant relationship between the polymerization condition and the failure pattern (Fig. 2 Right). Furthermore, no significant difference in bonding strength of Unifast Trad to denture base resin surface-treated without primer was observed under any curing condition (Fig. 3 Left). Most surfaces exhibited interface failure, and there was no significant correlation between the curing condition and the failure pattern (Fig. 3 Right). Although significant differences were found in the bonding strength of Unifast Trad to denture base resin surface-treated with primer between curing conditions $\mathrm{L}$ and $\mathrm{N}$, no significant correlation was observed between the curing condition and the 

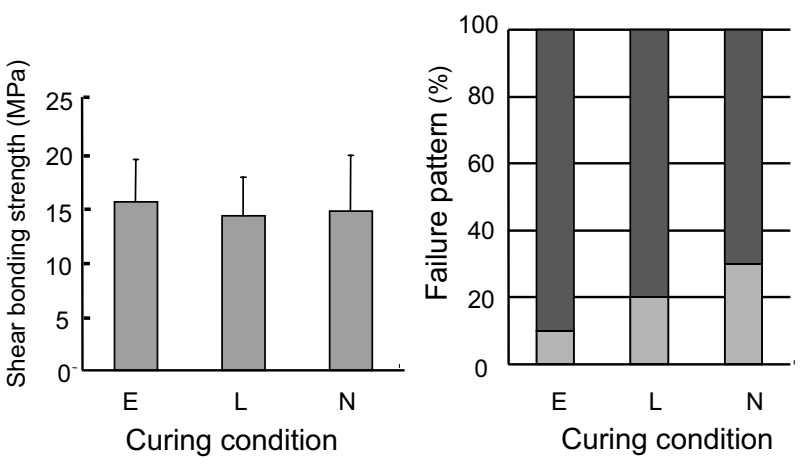

Interface failure cohesion failure

Fig. 3 Results for shear bonding strength and failure pattern for Unifast Trad to denture base resin surface-treated without primer $(\mathrm{N}=10)$. ( $*: P<.05$, T-bar: S.D. $)$

failure pattern, since all failure patterns were represented by cohesion failure (Fig. 4).

\section{Discussion}

In prosthodontic treatment, self-curing resins are frequently used for denture repair and provisional crowns. Although self-curing resins with tertiary amine as the polymerization initiator are widely used, they are associated with the problem of discoloration with time after polymerization. This is a disadvantage, as a repaired denture is used for a relatively long time, unlike a provisional crown. Therefore, self-curing resins with barbituric acid derivatives as the polymerization initiator have recently come into more frequent use, as they offer greater stability of color. ${ }^{9}$ However, their bonding strength with the denture base resin is lower than that of self-curing resins with tertiary amines. ${ }^{4}$ One method of overcoming this drawback and improving the bonding strength is to apply alumina air abrasive, ${ }^{3,4,10}$ dichloromethane, ${ }^{3,4}$ acetone ${ }^{5}$ methylene chloride ${ }^{5}$ or methyl methacrylate $e^{2,5}$ at the adherent face. Minami et $\mathrm{al}^{10}$ found that the bonding strength of a self-curing resin to a denture base resin in a state of saturated water absorption was greater than that for a dry denture base resin, when its surface was untreated. There was no significant difference, however, when the adherent face was treated with dichloromethane. They speculated that this was because the water suppressed heat generation during the polymerization, thereby slowing the rate of polymerization, and that the prolonged period until completion of polymeriza-
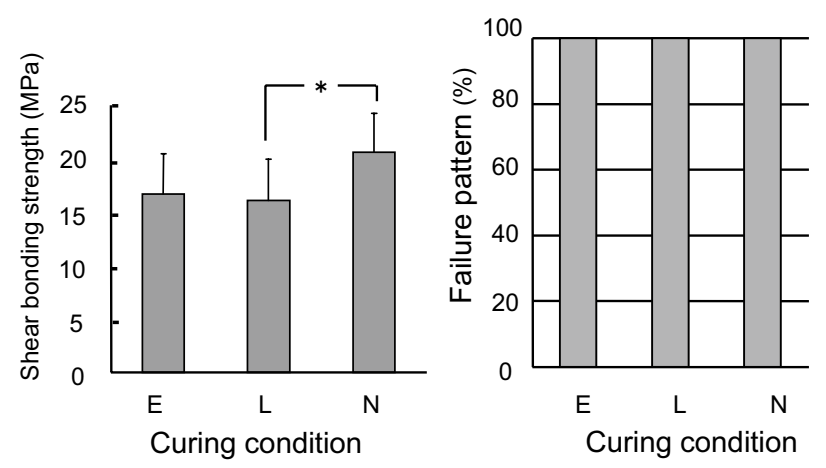

Interface failure cohesion failure

Fig. 4 Results for shear bonding strength and failure pattern for Unifast Trad to denture base resin surface-treated with primer $(\mathrm{N}=10) .(*: P<.05$, T-bar: S.D. $)$

tion results in increased diffusion of the resin monomers.

We found that the bonding strength of Unifast II was lower than that of Unifast Trad when no primer was used for the surface treatment of the denture base, whereas no significant difference in the bonding strength between the two was observed when primer was used for the surface treatment. These results are consistent with those reported from previous studies. ${ }^{3,4}$ In addition, not all the failure patterns of Unifast Trad were represented by cohesion failure; therefore, it is also important to enhance the bonding strength of Unifast Trad.

Bonding strength under curing condition $\mathrm{E}$ was greater than that under curing conditions $\mathrm{L}$ and $\mathrm{N}$ when no primer was applied for surface treatment. We believe that this might be due to the improved bonding strength resulting from the increased generation of radicals caused by warming at initial polymerization. Hoshiai et $\mathrm{al}^{7}$ compared the bonding strength between a selfcuring resin and another cured self-curing resin. They tested conditions set at 30 or 60 s prior to immersion for 30 or $60 \mathrm{~s}$, and found no influence of the conditions on the bonding strength. Taken together with our results, it is clear that initial warming within 30 s enhances the bonding strength. Warming accelerates the polymerization rate, therefore reduces the time taken for polymerization. Therefore, extreme warming may lead to completion of polymerization prior to progress in diffusion of the monomer.

The effects of warming during polymerization on the strength and deformation of a self-curing 
resin also need to be considered. ${ }^{6,11}$ Ogawa and Hasegawa ${ }^{12}$ studied the effects of the curing environment-air or water with/without pressure and air or water temperature during polymerizationon the strength, stiffness, and hardness during the polymerization of a self-curing resin. They found that a polymerization under high-temperature, high-pressure, and wet conditions increased the strength and stiffness of the self-curing resin. As compared with the dry condition, however, a wet condition reduced the surface hardness of the resin. As described above, since many factors influence the bonding strength of a self-curing resin to a denture base resin, determining the polymerization conditions for obtaining the optimal bonding strength between these two resins may require a multivariate analysis. This study only evaluated the initial bonding strength, thus the long-term bonding strength needs to be evaluated in a future study. Further research is also necessary to clarify failure patterns, as our results revealed cohesion failures in the self-curing resin, in the denture base resin, or in both.

Based on the above results on the initial bonding strength between denture base and selfcuring resins, we conclude that: (i) for Unifast II built up on denture base resin surface-treated without primer, immersion in warm water at the initiation of polymerization of the self-curing resin is effective for enhancing the bonding strength, and (ii) for both Unifast II built up on a denture base surface-treated with primer and Unifast Trad built up on a denture base surfacetreated with and without primer, there was no correlation between immersion in warm water during polymerization and the bonding strength.

Acknowledgment: We are very grateful to Mr. Jeremy Williams for his assistance with the revision of the English language in this manuscript.

\section{References}

1. Shimizu H, Habu T, Naka S et al. Treatment agents for denture base resin. Part 1: The effect of organic solvents, J Jpn Prosthodont Soc 38: 119-125, 1994.

2. Vallittu PK, Lassila VP, Lappalainen R. Wetting the repair surface with methyl methacrylate affects the transverse strength of repaired heat-polymerized resin. J Prosthet Dent 72: 639-643, 1994.

3. Shimizu H, Habu T, Naka S et al. Surface treatment agents for denture base resin. Part 3: Evaluation by shear bond strength test and three-point loading test and comparison of effects between for heat-cured denture base resin and pour-type one. J Jpn Prosthodont Soc 40: 1063-1070, 1996.

4. Shimizu H, Yoshinaga M, Habu T et al. Bond strength of a self-curing resin with barbituric acid derivatives to a few kinds of denture base resin in denture repair. J Jpn Prosthodont Soc 42: 815-822, 1998.

5. Sarac YS, Sarac D, Kulunk T et al. The effect of chemical surface treatments of different denture base resins on the shear bond strength of denture repair. J Prosthet Dent 94: 259-266, 2005.

6. Ogawa T, Tanaka M, Koyano K. Effect of water temperature during polymerization on strength of autopolymerizing resin. J Prosthet Dent 84: 222-224, 2000.

7. Hoshiai K, Tanaka Y, Tadakoshi T et al. The most adequate conditions in clinical usage of autopolymerizing resin with barbituric acid derivatives. J Jpn Prosthodont Soc 46: 233-240, 2002.

8. Shimizu H, Habu T, Mori N et al. Shear bond strength testing method in removable prosthodontics. Adhesive Dentistry 14: 111-122, 1996.

9. Hoshiai K, Tanaka Y, Hiranuma K. Comparison of a new autocuring temporary acrylic resin with some existing products. J Prosthet Dent 79: 273-277. 1998.

10. Minami H, Suzuki S, Minesaki Y et al. In vitro evaluation of the influence of repairing condition of denture base resin on the bonding of autopolymerizing resins. J Prosthet Dent 91: 164-170, 2004.

11. Ogawa T, Aizawa S, Tanaka M et al. Effect of water temperature on the fit of provisional crown margins during polymerization. J Prosthet Dent. 82: 658-661, 1999.

12. Ogawa T, Hasegawa A. Effect of curing environment on mechanical properties and polymerizing behaviour of methyl-methacrylate autopolymerizing resin. J Oral Rehabil 32: 221-226, 2005. 